Door: Charlotte Germonpré (charlotte.germonpre@ugent.be), Robrecht Raedt, neurowetenschappen, Veerle de Herdt, neurologie, 4BRAIN, Universiteit Gent, België.

\title{
Epileptische aanvallen in een ratmodel voor hersenbloeding
}

Het optreden van een hersenbloeding is een risicofactor voor het ontwikkelen van epilepsie. Tot op heden zijn er weinig preklinische studies die het mechanisme van aanvallen na een hersenbloeding onderzoeken. Het doel van deze studie was het ontwikkelen van een diermodel dat spontane aanvallen vertoont na een hersenbloeding. Met behulp van een dergelijk model kan het effect van deze aanvallen op functionele uitval en secundaire hersenschade onderzocht worden.

Beroertes of cerebrovasculair accidents (CVA's) kunnen worden onderverdeeld in twee verschillende categorieën; enerzijds als een ischemische beroerte en anderzijds als een hersenbloeding. Bij een ischemische beroerte wordt de bloedtoevoer naar de hersenen verhinderd door een trombus. Een hersenbloeding treedt op wanneer een bloedvat scheurt waardoor er bloed lekt in het hersenweefsel. Een frequente oorzaak is een onderliggende aandoening van de bloedvaten, die in de meerderheid van de gevallen gerelateerd is aan hypertensie. Hoewel een hersenbloeding slechts optreedt in 10-20\% van de patiënten met een beroerte, is dit de meest ernstige vorm met een hoge morbiditeit en mortaliteit: een van de drie patiënten overlijdt binnen een periode van 30 dagen (Pinho et al., 2019).

\section{Epilepsie na een beroerte}

Eén van de complicaties na een beroerte is het optreden van epileptische aanvallen. Ongeveer I4 tot I $6 \%$ van de patiënten met een hersenbloeding ondervindt vroegtijdige epileptische aanvallen, dat wil zeggen tijdens de eerste dagen na de bloeding (De Herdt et al., 20II; Pinho et al., 20r9). Deze aanvallen zijn mogelijk te wijten aan acute
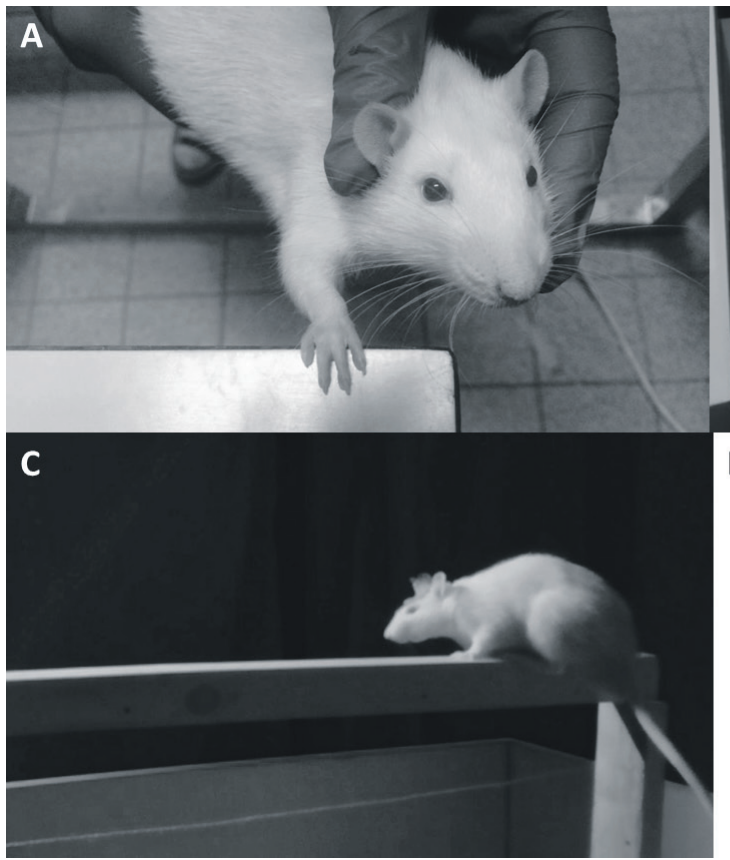

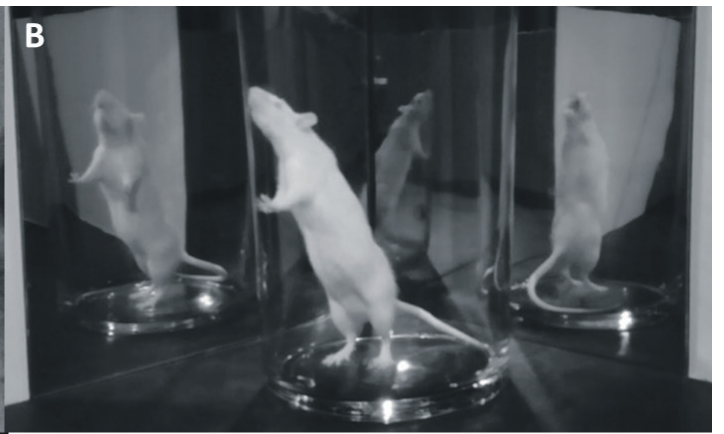

D Cilindertest

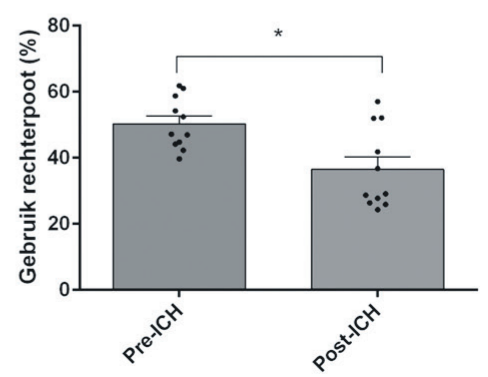

Figuur 1 A) Forelimb placing test. B) Cilindertest. C) Mogelijkheid om over een houten balk te lopen, onderdeel van de neurological deficit scale. D) Resultaten van cilindertest, voor en na de bloeding. 
metabole en fysiologische veranderingen in de hersenen ten gevolge van de bloeding en beschouwt men als acuut symptomatische epileptische aanvallen (Silverman et al., 2002). De corticale betrokkenheid van de bloeding is geassocieerd met een vergroot risico op dergelijke vroegtijdige aanvallen (De Herdt et al., 20II). De diagnose van epilepsie wordt pas gesteld bij aanvallen die meer dan één week na de beroerte optreden. Hier spelen permanente veranderingen in de exciteerbaarheid van de hersenen een rol. Ongeveer Io\% van de patiënten met een hersenbloeding wordt uiteindelijk met epilepsie gediagnosticeerd (Pinho et al., 2019).

\section{Het diermodel}

Het rat collagenase model is een model dat frequent gebruikt wordt om pathofysiologie van hersenbloedingen en potentiële neuroprotectieve behandelingen te bestuderen. In dit diermodel, dat in I99o werd ontwikkeld door Rosenberg, wordt collagenase, een enzym, geïnjecteerd in terwijl in het autoloog bloedmodel geen gebruik wordt gemaakt van een enzym dat op zich al een lokale inflammatoire reactie kan veroorzaken.

Epileptische aanvallen zijn frequent bestudeerd in diermodellen voor ischemische beroerte, maar nauwelijks in diermodellen voor hersenbloeding. Eén studie detecteerde geen epileptische aanvallen in het autoloog bloedmodel, maar vond epileptische aanvallen in $66 \%$ van de dieren geïnjecteerd met collagenase (Klahr et al., 2015). In deze studie werd enkel gekeken naar het optreden van aanvallen met behulp van elektro-encefalografie (EEG) zonder correlatie met gedrag.

De studie

Het doel van deze studie was het ontwikkelen van een diermodel dat spontane epileptische aanvallen vertoont na inductie van een hersenbloeding door middel van collagenase injectie. Acuut symptomatische epileptische

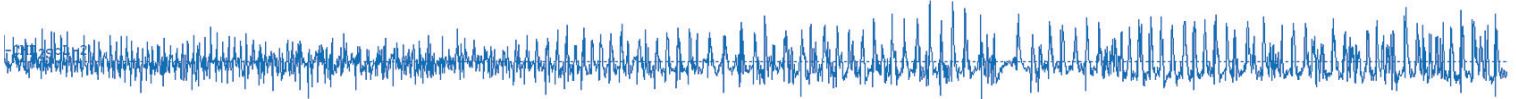

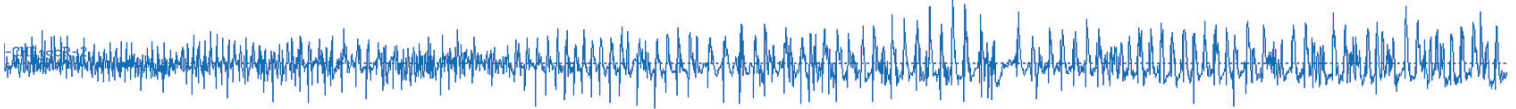

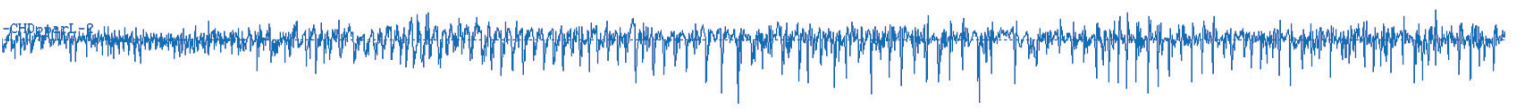

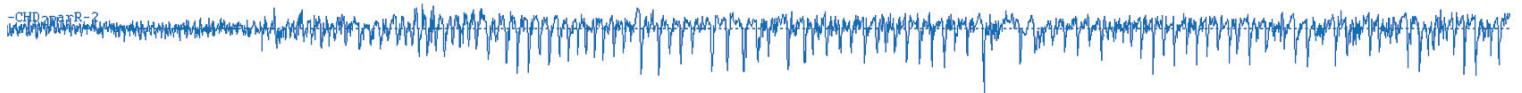

Figuur 2 Voorbeeld van een EEG waarin een epileptische aanval zichtbaar is na een intracerebrale bloeding.

het hersenweefsel van een rat, waardoor het collageen in de bloedvatwand afgebroken wordt (Rosenberg et al., I990). Na enkele uren ontstaat er een bloeding, waarbij de grootte dosisafhankelijk is. Een hersenbloeding kan ook geïnduceerd worden door autoloog bloed te injecteren in de hersenen van het dier, het zogenaamde autoloog bloedmodel (Bullock et al., I984). Deze modellen hebben elk hun voor- en nadelen. Het collagenase model weerspiegelt de klinisch geobserveerde groei van het hematoom en oedeem tijdens de eerste uren en dagen na de bloeding, aanvallen werden bestudeerd door middel van continue video-EEG monitoring. Tijdens deze studie werd gebruik gemaakt van dertien ratten en alle experimenten werden goedgekeurd door de Ethische Commissie Dierproeven van de Universiteit Gent (ECD I6/5I). Corticaal EEG en het gedrag van de dieren werden gedurende één week continu opgenomen met video-EEG apparatuur, om eventuele epileptische aanvallen geïnduceerd door de operatie uit te sluiten. Vervolgens werden de dieren opnieuw verdoofd om collagenase (o.6 U) of een steriele zoutop- 


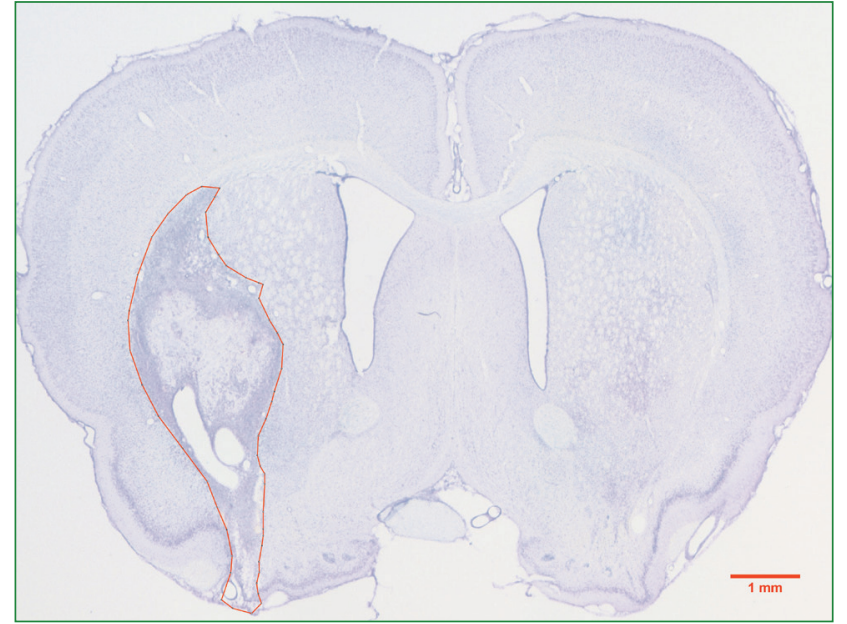

Figuur 3 Voorbeeld van een intracerebrale bloeding. Bloeding is in het rood omlijnd.

lossing $(\mathrm{n}=2)$ te injecteren in het linker striatum, waarna ze gedurende één week verder werden gemonitord met video-EEG om het optreden van epileptische aanvallen door de hersenbloeding na te gaan. Om het effect van de hersenbloeding op motorische functies te meten werden er op verschillende tijdstippen na de bloeding gedragstesten uitgevoerd.

In dit onderzoek werd onder andere gebruik gemaakt van de forelimb placing test, waarbij getest wordt of de rat zijn voorpoot kan plaatsen op een tafelrand na prikkeling van de snorharen tegen de tafelhoek (figuur IA). De cilindertest werd gebruikt om na te gaan of ratten hun beide voorpoten even veel tegen de wand van een glazen cilinder plaatsen, wat het geval is bij gezonde dieren (figuur IB). $\mathrm{Na}$ inductie van de hersenbloeding gebruiken de ratten minder hun rechter voorpoot om de wand van de cilinder te exploreren (gepaarde t-test, $\mathrm{p}=\mathrm{o} . \mathrm{ooI}$ ). Ten slotte werd ook gebruik gemaakt van de neurological deficit scale. Deze evaluatie bestaat uit vijf verschillende testen, waarbij het dier onder andere over een smalle houten balk moet lopen (figuur IC). Op het einde van het experiment werden de dieren geëuthanaseerd om het volume en de locatie van de bloeding te bepalen door middel van histologie.

\section{Resultaten en discussie}

Implantatie van elektroden op de hersenschors gaf geen aanleiding tot epileptische aanvallen. Inductie van een hersenbloeding door injectie van collagenase met een dosis van o.6 $\mathrm{U}$ veroorzaakte epileptische aanvallen in $45 \%$ van de dieren in de eerste dagen na injectie. Het grootste deel van deze aanvallen (87\%) was te zien op EEG en video, $13 \%$ van de aanvallen was enkel te zien op het EEG (figuur 2). Dit fenomeen, dat niet alle aanvallen na een hersenbloeding zich klinisch uiten, wordt ook gezien bij patiënten: in $28 \%$ van de patiënten werden aan- vallen gedetecteerd met behulp van EEG (Pinho et al., 2019).

De inductie van een hersenbloeding door injectie met o, 6 $\mathrm{U}$ collagenase gaf in onze studie geen aanleiding tot mortaliteit. Histologie toonde aan dat in alle dieren een bloeding aanwezig was, met een gemiddeld volume van $27 \mathrm{~mm}$ en dat de bloeding zich in de meeste gevallen uitstrekte tot de piriforme cortex (figuur 3). Er kon echter geen significant verband aangetoond worden tussen het voorkomen van epileptische aanvallen en de corticale betrokkenheid van de bloeding (De Herdt et al., 20II). Een hersenbloeding heeft, zoals verwacht, ook negatieve effecten op de gedragstesten. Onder andere in de cilindertest werd een significant verschil aangetoond voor en na de bloeding: na de hersenbloeding in het linker striatum gebruiken de ratten hun rechterpoot minder dan hun linkerpoot (zie figuur ID). Er werd geen verschil gevonden in motorische functie wanneer de dieren met epileptische aanvallen vergeleken werden met de dieren zonder epileptische aanvallen.

\section{Conclusie}

Het ratmodel waarbij o. $6 \mathrm{U}$ collagenase wordt geïnjecteerd in het striatum is een bruikbare methode om acuut symptomatische aanvallen na een hersenbloeding te bestuderen. Dit model geeft aanleiding tot een hersenbloeding in alle dieren zonder mortaliteit te veroorzaken en veroorzaakt in $45 \%$ van de dieren epileptische aanvallen in de eerste dagen na de bloeding.

\section{Referenties}

Bullock R, Mendelow AD, Teasdale GM et al. (I984) Intracranial haemorrhage induced at arterial pressure in the rat. Part I: Description of technique, ICP changes and neuropathological findings. Neurological Research. 6:184-188.

De Herdt V, Dumont F, Hénon H et al. (20II) Early seizures in intracerebral hemorrhage: Incidence, associated factors and outcome. Neurology. 77:1794-1800.

Klahr AC, Dickson CT, Colbourne F (2015) Seizure activity occurs in the collagenase but not the blood infusion model of striatal hemorrhagic stroke in rats.

Translational Stroke Research. 6:29-38.

Pinho J, Costa A, Araújo J et al. (2019) Intracerebral hemorrhage outcome: A comprehensive update. Journal of the Neurological Sciences. 398:54-66.

Rosenberg GA, Mun-Bryce S, Wesley M et al. (I990) Collagenase-induced intracerebral hemorrhage in rats. Stroke. 21:801-807.

Silverman IE, Restrepo L, Mathews GC (2002) Poststroke seizures. Arch Neurol. 59:195-201. 